\title{
The effect of unobserved preferences and race on vaccination hesitancy for COVID-19 vaccines: implications for health disparities
}

\author{
Eline M van den Broek-Altenburg, PhD; Adam J Atherly, PhD; Stephane Hess, PhD; and Jamie Benson, BA
}

\begin{abstract}
BACKGROUND: Reducing the extra burden COVID-19 has on people already facing disparities is among the main national priorities for the COVID-19 vaccine rollout. Early reports from states releasing vaccination data by race show that White residents are being vaccinated at significantly higher rates than Black residents. Public health efforts are being targeted to address vaccine hesitancy among Black and other minority populations. However, health care interventions intended to reduce health disparities that do not reflect the underlying values of individuals in underrepresented populations are unlikely to be successful.
\end{abstract}

OBJECTIVE: To identify key factors underlying the disparities in COVID-19 vaccination.

METHODS: Primary data were collected from an online survey of a representative sample of the populations of the 4 largest US states (New York, California, Texas, and Florida) between August 10 and September 3, 2020.
Using latent class analysis, we built a model identifying key factors underlying the disparities in COVID-19 vaccination.

RESULTS: We found that individuals who identify as Black had lower rates of vaccine hesitancy than those who identify as White. This was true overall, by latent class and within latent class. This suggests that, contrary to what is currently being reported, Black individuals are not universally more vaccine hesitant. Combining the respondents who would not consider a vaccine $(17 \%)$ with those who would consider one but ultimately choose not to vaccinate ( $11 \%)$, our findings indicate that more than 1 in 4 (28\%) persons will not be willing to vaccinate. The no-vaccine rate is highest in White individuals and lowest in Black individuals.

CONCLUSIONS: Results suggest that other factors, potentially institutional, are driving the vaccination rates for these groups. Our model results help point the way to more effective differentiated policies.
Reducing health disparities has become a national priority, ${ }^{1-3}$ especially during the COVID-19 vaccine rollout. On December 14, 2020, the first Americans received a COVID-19 vaccine outside the ongoing clinical trials. As the supply of vaccines was limited at first, the Centers for Disease Control Prevention (CDC) Advisory Committee in Immunization Practices (ACIP) recommended that initial supplies of COVID-19 vaccine be allocated to health care personnel and long-term care facility residents, followed by frontline essential workers and people aged 75 years and older. ${ }^{4}$ Among their 3 main goals for whom should be offered COVID-19 vaccines, the first was to reduce the extra burden COVID-19 has on people already facing disparities.

Research has consistently shown that the COVID-19 pandemic is disproportionally affecting those who

\section{Author affiliations}

Eline M van den Broek-Altenburg, PhD; Jamie S. Benson, BA; and Adam J Atherly, PhD, Larner College of Medicine, University of Vermont, Burlington. Stephane Hess, $\mathrm{PhD}$, Choice Modelling Centre and Institute for Transport Studies, University of Leeds, United Kingdom.

AUTHOR CORRESPONDENCE:

Eline van den Broek, 802.495.6029;

eline.altenburg@med.uvm.edu

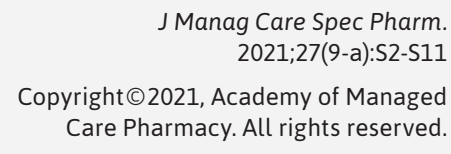

are in already disadvantaged situations or groups..$^{5,6}$ Early data from the COVID-19 pandemic showed that Black and Latino populations in the United States were 3 times more likely to contract COVID-19 than White residents and nearly twice as likely to die from it. ${ }^{7}$ This is reflected in initial barriers to vaccine access. ${ }^{8}$ Early reports also show disparities in vaccination rates: Black Americans were receiving COVID-19 vaccinations 
at dramatically lower rates than White Americans in the first weeks of the rollout. ${ }^{9}$ In the states that have released vaccination data by race, White residents were being vaccinated at significantly higher rates than Black residents, in some cases 2 to 3 times higher..$^{10}$ Recent reporting data also showed that the share of vaccinations among Black and Hispanic residents is smaller than their share of deaths in their states; for the Hispanic population, it is also smaller than their share of COVID-19 cases. $^{9}$

The reason for the differing rates of vaccinations is unclear. The inequality could be caused by structural or systematic racism ${ }^{11}$ or by higher vaccine hesitancy among Black and Hispanic communities or by other factors. ${ }^{12,13}$ Beckman et al recommended that health care providers engage with these communities to overcome vaccine hesitancy and provide appropriate public health information..$^{14,15}$ However, these collective efforts do not acknowledge that vaccine hesitancy can be caused by a myriad of underlying differences among subgroups-or that the difference could be due to factors other than hesitancy. Potential other factors range from easily observable attributes, such as lack of income or education, to attributes that are harder to observe such as effects of structural or institutional racism. The objective of this study was to identify key factors underlying the disparities in COVID-19 vaccination.

\section{Methods}

\section{DATA AND STUDY DESIGN}

Our data are based on a survey of a representative sample of the population of the 4 largest US states (New York, California, Texas, and Florida). Respondents were sampled from an online Qualtrics panel from August 10 through September 3, 2020 , and were representative with respect to the state and US population in terms of age, gender, and race.

Participants were asked to imagine a situation where a number of vaccines for COVID-19 had been developed. These vaccines would have undergone all required testing and received regulatory approval for use in humans. They were then presented with 6 scenarios, or choice tasks, where in each task, 2 possible vaccines were described with the following 7 attributes: (1) risk of infection-the number out of every 100,000 vaccinated people who would still get infected when coming in contact with an infected person; (2) risk of serious illness-the number out of every 100,000 vaccinated people who, if infected, would develop serious symptoms; (3) estimated protection duration-the expected length of time that the protection provided by the vaccine will last before a new course of vaccination is needed; (4) risk of mild side effects (such as numbness or a rash at the injection site, or a headache)-the number of people out of 100,000 that suffer mild side effects from the vaccine; (5) risk of severe side effects (such as an allergic reaction requiring further medical treatment)-the number of people out of 100,000 that suffer severe side effects from the vaccine; (6) waiting time-how long people need to wait to obtain the vaccine for free; and (7) fee-how much people need to pay to obtain the vaccine immediately.

The vaccines also varied by 2 key population attributes: (1) population coverage: the share of the population that have already been vaccinated, and (2) exemption from international travel restrictions: the exemption from travel restrictions related to COVID-19 for vaccinated people. This includes quarantine in some countries before and/or after travel.

In each scenario, respondents were asked to choose 1 of the 2 offered vaccines or choose to not be vaccinated. If they chose 1 of the vaccines, they would have the option to wait and be vaccinated for free or to pay for immediate vaccination. The levels for the attributes that describe the vaccines that respondents were asked to choose between varied across the choice tasks.

Our initial sample was 475 . We excluded observations with an unrealistic pattern of always choosing the option on the left $(n=22)$ and missing demographic information such as age, race, income, or education $(n=1)$ for a final sample size of 452 .

\section{ANALYTIC APPROACH ADDRESSING HEALTH DISPARITIES}

Pursuing health equity means pursuing the elimination of health disparities between all groups in a given category. ${ }^{12}$ Typical value assessment methods in health, including cost-effectiveness and health outcomes, generally account for health disparities by using observed differences between the most advantaged group in a given category (income, race, etc) and disadvantaged groups. Standard analysis of a "representative" sample-including underrepresented populations-yields average effects across the entire population.

There are a number of methodological approaches available that incorporate differences in individual preferences. In particular, notwithstanding extensions to nonlinear specifications, the utility for a given alternative 


\begin{tabular}{|c|c|c|}
\hline & $\begin{array}{c}\text { Population } \\
\%\end{array}$ & $\begin{array}{c}\text { Sample mean } \\
n(\%) \\
(\mathbf{N}=387)\end{array}$ \\
\hline \multicolumn{3}{|l|}{ Sex } \\
\hline Male & 49.2 & $191(49.4)$ \\
\hline Female & 50.8 & $196(50.6)$ \\
\hline \multicolumn{3}{|l|}{ Age (years) ${ }^{a}$} \\
\hline Younger than 30 & 22.9 & $82(21.2)$ \\
\hline $31-40$ & 17.1 & $69(17.8)$ \\
\hline $41-50$ & 15.8 & $113(29.2)$ \\
\hline $51-60$ & 16.7 & $48 \quad(12.4)$ \\
\hline Older than 60 & 27.5 & $75 \quad(19.4)$ \\
\hline \multicolumn{3}{|l|}{ Race $^{\text {b }}$} \\
\hline White & 76.3 & $294(76.0)$ \\
\hline Black & 13.4 & $37 \quad(9.6)$ \\
\hline Asian & 5.9 & $22 \quad(5.7)$ \\
\hline Mixed & 2.8 & $18 \quad(4.7)$ \\
\hline Other & 1.6 & $10 \quad(2.6)$ \\
\hline Prefer not to say/missing & - & $6 \quad(1.6)$ \\
\hline \multicolumn{3}{|l|}{ Income (USD) } \\
\hline Less than $\$ 20,000$ & 13.1 & $56(14.5)$ \\
\hline$\$ 20,000-\$ 40,000$ & 15.9 & $72(18.6)$ \\
\hline$\$ 40,001-\$ 75,000$ & 24.6 & $89(23.0)$ \\
\hline More than $\$ 75,000$ & 46.4 & $155(40.1)$ \\
\hline Prefer not to say/missing & - & $15 \quad(3.9)$ \\
\hline
\end{tabular}

continued on next page

(say i) is typically given as a linear in attributes specification, such that

(1) $V_{i, n, t}=\beta_{n}{ }^{\prime} x_{i, n, t}=\sum_{k=1}^{K} \beta_{n, k} x_{i, n, t, k} V_{i, n, t}=\beta_{n}{ }^{\prime} x_{i, n, t}=\sum_{k=1}^{K} \beta_{n, k} x_{i, n, t, k}$

In this notation, $x_{i, n, t, k} x_{i, n, t, k}$ is a specific attribute (the kth attribute of $K$ ) of alternative $i$, as seen by person $n$ in choice situation $t$. The parameter $\beta_{n, k} \beta_{n, k}$ captures the marginal utility for person $\mathrm{n}$ in response to this attribute. Imagine for example that attribute $\mathrm{k}$ relates to the efficacy of a vaccine. We would then expect that $\beta_{n, k} \beta_{n, k}$ is positive, ie, that, as efficacy of a vaccine increases, so does its utility. The subscript $\mathrm{n}$ on $\beta_{n, k} \beta_{n, k}$ reflects the fact that different individuals will have different sensitivities to changes in the attributes.

In the simplest type of random utility model, the multinomial logit (MNL) model, which serves as the starting point for what follows, the probability of person $\mathrm{n}$ choosing option $\mathrm{i}$ in task $\mathrm{t}$ is given by

$$
\text { (2) } P_{n, t}\left(i \mid x_{n, t}, \Omega\right)=\frac{e^{v_{i, n, t}}}{\sum_{j=1}^{J} e^{v_{j, n, t}}} P_{n, t}\left(i \mid x_{n, t}, \Omega\right)=\frac{e^{v_{i, n, t}}}{\sum_{j=1}^{J} e^{v_{j, n, t}}},
$$

where $\Omega \Omega$ groups together the different model parameters. Returning to the above example of efficacy increasing for vaccine $i$ (of $J$ vaccines), this would imply that $V_{i, n, t} V_{i, n, t}$ increases too, and as a result, the probability of person $n$ choosing that vaccine becomes larger.

In the simplest approach, interaction terms can be used to allow differences in preferences across different groups. As long as the differences in preferences relate to differences in observed decision maker characteristics, this will be an effective approach.

A more subtle problem is the inclusion of unobserved preferences. Mixed logit models rely on using continuous statistical distributions to represent unobserved heterogeneity.

Unobserved factors that affect preferences such as personality traits (eg, extraversion) $)^{13}$; personal values such as universalism, spirituality, and moral values ${ }^{14}$; and distressing uncertainty, emotional distress, or religious affiliation or beliefs are often ignored, although there are models available that can account for such differences. For example, "mixed" multinomial logit models (MMNL) allow variation in preferences based on both observed and unobserved characteristics. Applications of MMNL in health include, but are certainly not limited to, estimating switching costs for health insurance ${ }^{15}$ analyzing patient preferences for provider choice, ${ }^{16}$ and analyzing patients' responsiveness to quality when choosing hospitals. There have also been numerous studies using MMNL models to analyze preferences for specific treatments or health services, such as for diabetes care ${ }^{17}$ men's preferences and trade-offs for prostate cancer screening, and patient preferences for managing asthma. ${ }^{18}$

A different approach is to use discrete (rather than continuous) distributions and probabilistically segmenting a sample population into different segments, such as latent class analysis (LCA). LCA explores deterministic heterogeneity by incorporating explanatory variables as multiplicative interaction terms. In a model with $\mathrm{S}$ different classes, each class would then be characterized by a different vector of parameters, say $\Omega_{s} \Omega_{s}$ for class s. This could, for example, capture the existence of one class of individuals who are particularly sensitive to efficacy, whereas another 


\section{TABLE 1}

Sample Descriptive Statistics (continued)

\begin{tabular}{l|c|c}
\hline & $\begin{array}{c}\text { Population } \\
\%\end{array}$ & $\begin{array}{c}\text { Sample mean } \\
\mathbf{n}(\%) \\
(\mathbf{N}=387)\end{array}$ \\
\hline Education $^{\mathrm{a}}$ & \multicolumn{2}{|l}{} \\
\hline
\end{tabular}

\begin{tabular}{l|r|r}
\hline None & 0.3 & \multicolumn{2}{|c}{-} \\
\hline Less than high school & 10.3 & $4 \quad(1.0)$ \\
\hline High school graduate/GED & 28.3 & $137(35.4)$ \\
\hline Associate degree & 9.8 & $71(18.3)$ \\
\hline Bachelor's degree & 21.3 & $114(29.5)$ \\
\hline Professional/graduate degree & 12.0 & $61(15.8)$
\end{tabular}

\begin{tabular}{l|r|r}
\hline Smoking status $^{\mathrm{b}}$ & \multicolumn{2}{l}{} \\
\hline Nonsmoker & 86.0 & 309 (79.8) \\
\hline Current smoker & 14.0 & 78 (20.2) \\
\hline
\end{tabular}

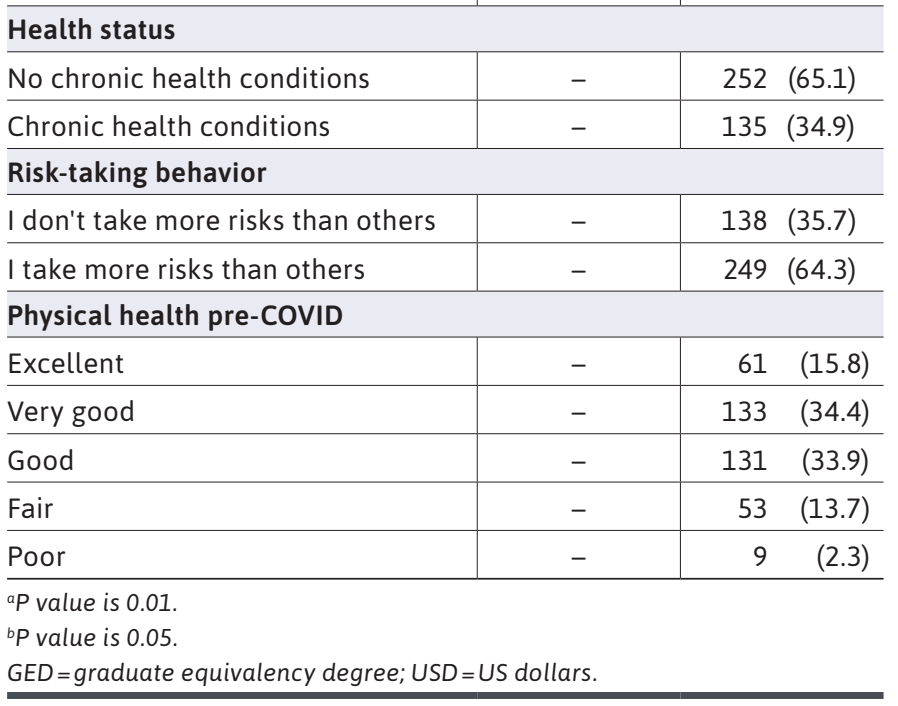

class is more sensitive to side effects. If we knew with certainty that person $\mathrm{n}$ falls into class $\mathrm{s}$, then the choice probability would simply be given by

$$
\text { (3) } P_{n, t, s}\left(j \mid x_{n, t}, z_{n}, \Omega_{\mathrm{s}}\right) P_{n, t, s}\left(j \mid x_{n, t}, z_{n}, \Omega_{\mathrm{s}}\right) \text {, }
$$

where this would be given by equation (2) when using an underlying MNL model inside each class. However, the actual class allocation is not observed deterministically, and a latent class structure consequently uses a class allocation model, where respondent $\mathrm{n}$ belongs to class $\mathrm{s}$ (of a total of $\mathrm{S}$ classes) with probability

$$
\text { (4) } \pi_{n, s} \text {, where } 0 \leq \pi_{n, s} \leq 1 \forall k \text { and } \sum_{s=1}^{S} \pi_{n, s}=1, \forall s \sum_{s=1}^{S} \pi_{n, s}=1, \forall s \text {. }
$$

These class allocation probabilities can vary across individual decision makers as a function of their observed

\begin{tabular}{l|c|c|c}
\cline { 2 - 4 } \multicolumn{1}{c}{ TABLE 2 } & \multicolumn{3}{|c}{ Predicted Vaccine Uptake } \\
\hline $\begin{array}{l}\text { Uaccine } \\
\text { uptake }\end{array}$ & $\begin{array}{c}\text { No } \\
\text { vaccine, } \%\end{array}$ & $\begin{array}{c}\text { Wait for free } \\
\text { vaccine, } \%\end{array}$ & $\begin{array}{c}\text { Pay for } \\
\text { immediate } \\
\text { access, \% }\end{array}$ \\
\hline $\begin{array}{l}\text { All respondents } \\
\text { Self-reported race }\end{array}$ & 10.6 & 59.9 & 29.5 \\
\hline White & 11.8 & 59.2 & 28.9 \\
\hline Black & 7.6 & 62.6 & 29.8 \\
\hline Asian & 7.6 & 62.4 & 30.0 \\
\hline Mixed & 12.0 & 62.4 & 30.1 \\
\hline Other & 58.6 & 29.4 \\
\hline
\end{tabular}

characteristics, ie, $\pi_{n, s}=h\left(z_{n}, \gamma\right) \pi_{n, s}=h\left(z_{n}, \gamma\right)$, where $\gamma \gamma$ is an additional vector of estimated parameters, and $z_{n} z_{n}$ are characteristics of the decision maker. Returning to the previously described example, this model component might, for example, explain that patients with preexisting health conditions are more likely to fall into the class that is more sensitive to side effects, whereas respondents with higher education levels might be more likely to fall into the class that is more sensitive to efficacy.

In contrast with the simple MNL model, the log-likelihood function uses a weighted average across separate submodels ( 1 for each class), with the weights given by the class allocation probabilities, such that

(5) $L L(x, z, \Omega, \gamma)=\sum_{n=1}^{N} \log \sum_{s=1}^{S} \pi_{n, s}\left[\prod_{t=1}^{T} P_{n, t, s}\left(\mathrm{Y}_{n, t} \mid x_{n, t}, \Omega_{\mathrm{s}}\right)\right] L L(x, z, \Omega, \gamma)=$

$$
\sum_{n=1}^{N} \log \sum_{s=1}^{S} \pi_{n, s}\left[\prod_{t=1}^{T} P_{n, t, s}\left(\mathrm{Y}_{n, t} \mid x_{n, t}, \Omega_{\mathrm{s}}\right)\right]
$$

where this is now also a function of the vector of parameters $\gamma$ used in the class allocation model, where $\Omega=<\Omega_{1}, \ldots, \Omega_{\mathrm{S}}>\Omega=<\Omega_{1}, \ldots, \Omega_{\mathrm{S}}>$ and where $Y_{n, t} Y_{n, t}$ is the observed choice for person $\mathrm{n}$ in task $t$.

Latent class models capture both observed and unobserved heterogeneity in preferences and are relatively new in health. ${ }^{19}$ LCA has been used to examine differential health preferences such as pharmaceutical preferences ${ }^{20,21}$; physician preferences ${ }^{19,22}$; patient-centered care $^{23}$; language used in palliative care consultations ${ }^{14}$; and specific treatments or diseases such as tuberculosis infection preventive treatment, ${ }^{24}$ community pharmacy asthma services,${ }^{25}$ and human papillomavirus vaccines among adolescent girls. ${ }^{26}$

Traditionally, subgroup analysis in health aims to determine heterogeneous treatment effects. In many applications, the subgroups will be homogeneous in their response, but it is possible to also allow for further heterogeneity within a class. Crucially, membership in the subgroup may differ by 


\section{TABLE 3 Sociodemographic Make-Up of Individual Classes}

\begin{tabular}{l|c|c|c}
\multirow{2}{*}{} & \multicolumn{3}{|c}{$\begin{array}{c}\text { Latent class difference from sample mean } \\
\text { (posterior estimation) }\end{array}$} \\
\cline { 2 - 4 } & $\begin{array}{c}\text { Class 1: } \\
\text { Anxious, \% }\end{array}$ & $\begin{array}{c}\text { Class 2: } \\
\text { Evaluative, \% }\end{array}$ & $\begin{array}{c}\text { Class 3: } \\
\text { Cost-conscious, \% }\end{array}$ \\
\hline No vaccine & 1.2 & 51.5 & 4.1 \\
\hline Wait for free vaccine & 36.8 & 36.2 & 89.3 \\
\hline Pay for immediate access & 61.8 & 12.3 & 6.6 \\
\hline
\end{tabular}

\begin{tabular}{|c|c|c|c|}
\hline \multicolumn{4}{|l|}{ Sex } \\
\hline Male (reference) & & & \\
\hline Female & -4 & -7 & 6 \\
\hline \multicolumn{4}{|l|}{ Age (years) ${ }^{a}$} \\
\hline Under 30 & 26 & -2 & -20 \\
\hline $31-40$ & -29 & -18 & 30 \\
\hline $41-50$ & -6 & 18 & -2 \\
\hline $51-60$ & 3 & 7 & -5 \\
\hline Over 60 & 5 & -13 & 1 \\
\hline \multicolumn{4}{|l|}{ Race $^{\text {b }}$} \\
\hline White & 0 & 7 & -2 \\
\hline Black & 8 & -2 & -5 \\
\hline Asian & -10 & -42 & 24 \\
\hline Mixed & -10 & -8 & 11 \\
\hline Other & 1 & -33 & 11 \\
\hline Prefer not to say/missing & 41 & -97 & 3 \\
\hline \multicolumn{4}{|l|}{ Income (USD) } \\
\hline Less than $\$ 20,000$ & 13 & 21 & -18 \\
\hline$\$ 20,000-\$ 40,000$ & 40 & -31 & -21 \\
\hline$\$ 40,001-\$ 75,000$ & -19 & -21 & 23 \\
\hline More than $\$ 75,000$ & -14 & 17 & 5 \\
\hline Prefer not to say/missing & - & - & - \\
\hline
\end{tabular}

\begin{tabular}{l|r|r|r}
\hline None & - & - & - \\
\hline Less than high school & -96 & 193 & 5 \\
\hline High school graduate/GED & 14 & -11 & -7 \\
\hline Associate's degree & 2 & 4 & -3 \\
\hline Bachelor's degree & -1 & -10 & 5 \\
\hline Professional/graduate degree & -26 & 25 & 11 \\
\hline Smoking status & &
\end{tabular}

\begin{tabular}{l|c|c|c}
\hline Smoking status $^{\mathrm{b}}$ & - & - & - \\
\hline Not a smoker & 4 & -14 & 2 \\
\hline Current smoker & \multicolumn{3}{|l}{} \\
\hline Drinking status & - & - & - \\
\hline Not a drinker & -24 & 11 & 16 \\
\hline Current drinker &
\end{tabular}

continued on next page health disparities. For example, there could be a subgroup of individuals who are hesitant to receive a COVID-19 vaccine. That group will act similarlynot based on health disparities-but membership within the group could be more likely for disadvantaged populations. ${ }^{27}$ The application of these methods in health can be valuable to support policy development and clinical practice, especially to account for individual drivers of health disparities.

The key analytic problem is thus the need to include in our model unobserved factors that affect preferences. To do this, we used a LCA, which addresses the issue of unobserved preferences by probabilistically segmenting a sample population into different groups or "classes".

\section{Results}

\section{VACCINE HESITANCY}

Overall, $15.7 \%$ of respondents indicated they would not accept a COVID-19 vaccine, either because of attribute levels or regardless of its attributes. Of these, $14.7 \%$ identified as White and $2.4 \%$ as non-White (ie, $1.3 \%$ Black, $0.5 \%$ mixed race, and $0.5 \%$ other). Of Black residents in the sample, $10.9 \%$ were in this group completely unwilling to consider a vaccine, regardless of any other factor. Of White respondents, $16.8 \%$ would not consider a vaccine, a higher proportion than among Blacks.

Of the $10.9 \%$ of Black respondents who indicated they would not consider a vaccine, $60 \%$ said that vaccines will need to undergo more testing before they would trust them, 20\% selected "I prefer obtaining immunity naturally without vaccination," and $20 \%$ selected "I do not believe in the benefits of vaccination." These motivations were different among White respondents, where $37.7 \%$ answered vaccines would need to undergo more testing, 31.1\% said they preferred 


\section{TABLE 3} Sociodemogra
(continued)

\begin{tabular}{|c|c|c|c|}
\hline & \multicolumn{3}{|c|}{$\begin{array}{l}\text { Latent class difference from sample mean } \\
\text { (posterior estimation) }\end{array}$} \\
\hline & $\begin{array}{l}\text { Class 1: } \\
\text { Anxious, \% }\end{array}$ & $\begin{array}{c}\text { Class 2: } \\
\text { Evaluative, \% }\end{array}$ & $\begin{array}{c}\text { Class 3: } \\
\text { Cost-conscious, \% }\end{array}$ \\
\hline \multicolumn{4}{|l|}{ Health status } \\
\hline No chronic health conditions & - & - & - \\
\hline Chronic health conditions & 2 & -34 & 11 \\
\hline \multicolumn{4}{|l|}{ Risk-taking behavior } \\
\hline I don't take more risks than others & - & - & - \\
\hline I take more risks than others & 3 & -9 & 1 \\
\hline \multicolumn{4}{|l|}{ Physical health pre-COVID } \\
\hline Excellent & -17 & 61 & -9 \\
\hline Very good & 4 & 24 & -12 \\
\hline Good & - & -33 & 12 \\
\hline Fair & 12 & -54 & 10 \\
\hline Poor & -6 & 26 & -4 \\
\hline $\begin{array}{l}\text { aP value is } 0.01 \\
\text { bP value is } 0.05 \\
\text { USD }=\text { US dollars. }\end{array}$ & & & \\
\hline
\end{tabular}

obtaining immunity naturally without vaccination, $11.5 \%$ said they do not believe in the benefits of vaccination, $6.6 \%$ said the options offered were not good enough compared with not being vaccinated, 3.3\% responded "enough people will accept vaccination so I will benefit from herd immunity," and 9.8\% had some other reason.

The $15.7 \%$ of respondents who indicated they would not accept a COVID-19 vaccine were excluded from the analysis.

\section{SAMPLE CHARACTERISTICS}

Table 1 reports the sample characteristics for gender, age groups, race, income, education, smoking status, whether or not respondents had a chronic condition, smoking status, drinking status, and whether they were more likely to take risks than others (self-assessed) among those who indicated a willingness to consider a vaccine.

Our sample included 50.6\% females; $21.1 \%$ of respondents aged younger than 30 years; $17.8 \%$ aged $31-40$ years; $29.2 \%$ aged $41-50$ years; $12.4 \%$ aged 51-60 years, and $19.4 \%$ aged older than 60 years. In our sample, $77.4 \%$ of respondents were White and $22.6 \%$ non-White; of which $13.4 \%$ were Black, 5.9\% Asian, 2.8\% mixed, and 1.6\% "other." We compared sample characteristics with US census data using chi-square tests and we found that the sample was representative at the $5 \%$ significance level for gender, age, race, and education $(\mathrm{P}<0.001)$.

\section{LATENT CLASS ANALYSIS}

The LCA showed that there was the appropriate number of classes to fit our data. The model probabilistically segmented respondents into a class with an overall preference for the paid vaccine options (Class 1); a class dominated by respondents who were most likely to choose the "no vaccine" option (Class 2); and a class that highly valued the free vaccine options (Class 3). Class 1 thus predominantly represents "anxious" individuals, Class 2 the "evaluative" individuals, and Class 3 the "cost-conscious" individuals.

Table 2 reports the predicted vaccine take-up based on the 3-class LCA, overall and by race. The results show that approximately $11 \%$ of the overall sample that would consider a vaccine would ultimately choose to forgo vaccination once they considered potential side effects, while $60 \%$ would accept a vaccine but would be unwilling to pay even $\$ 100$ for it, and $30 \%$ would like immediate access and would be willing to pay for quicker access. There was little difference in the proportions across races, except that White respondents reported a lower overall willingness to vaccinate.

Table 3 presents a more nuanced breakdown by class, and it clarifies if there are fewer or more individuals with particular characteristics in Class 1, Class 2, or Class 3. For example, there are $2 \%$ fewer individuals in Class 2 in the age group younger than 30 years and $20 \%$ fewer individuals in Class 3 than the total sample mean for that age group. In Class 1, 62\% of respondents preferred a vaccine option that would require them to pay a fee, but not wait. In Class 2, 52\% of respondents chose the "no vaccine" option most often, meaning that they did not like the other options given to them. In Class 3, 89\% of respondents preferred vaccine options that were given for free, but with a wait time.

Table 3 also shows predictions of class membership based on sociodemographic characteristics and class differences from the survey sample mean. To get a better understanding of the sociodemographic make-up of 


\section{TABLE 4 Latent Class Nested Logit Models with Interactions}

\begin{tabular}{|c|c|c|c|}
\hline Model description & \multicolumn{3}{|c|}{ LC-NL, 3 classes, with interaction } \\
\hline Number of individuals & \multicolumn{3}{|c|}{387} \\
\hline Number of observations & \multicolumn{3}{|c|}{2,322} \\
\hline Estimated parameters & \multicolumn{3}{|c|}{51} \\
\hline Log likelihood & \multicolumn{3}{|c|}{$-2,968.62$} \\
\hline Parameter & Class 1 & Class 2 & Class 3 \\
\hline ASC: position & $0.127^{b} \quad(0.047)$ & $0.028 \quad(0.048)$ & $0.054 \quad(0.042)$ \\
\hline ASC: free option & $0.894 \quad(0.83)$ & $-1.217^{b} \quad(0.533)$ & $0.245 \quad(0.437)$ \\
\hline ASC: paid option & $2.148^{\mathrm{b}} \quad(0.821)$ & $-1.79^{\mathrm{b}} \quad(0.603)$ & $-1.675^{c} \quad(0.489)$ \\
\hline ASC: no vaccine & - & - & - \\
\hline Risk of infection & $-0.023 \quad(0.039)$ & $-0.013 \quad(0.039)$ & $-0.161^{c} \quad(0.037)$ \\
\hline Risk of illness & $-0.071^{c} \quad(0.02)$ & $-0.044^{\mathrm{a}} \quad(0.025)$ & $-0.077^{c} \quad(0.02)$ \\
\hline Unknown protection duration & - & $0.097 \quad(0.206)$ & - \\
\hline Protection duration & $0.017^{c} \quad(0.004)$ & $0.001 \quad(0.004)$ & $0.022^{c} \quad(0.004)$ \\
\hline Mild side effects & $0.013 \quad(0.019)$ & $-0.026 \quad(0.02)$ & - \\
\hline Severe side effects & $-15.751 \quad(10.367)$ & $-29.487^{a}(16.156)$ & $-35.872^{c}(10.756)$ \\
\hline Wait time, months & $-0.006 \quad(0.012)$ & $-0.026^{\mathrm{b}} \quad(0.013)$ & $-0.013^{a} \quad(0.008)$ \\
\hline Fee, USD & $-0.003^{c} \quad(0.001)$ & $-0.002^{\mathrm{a}} \quad(0.001)$ & $-0.003^{b}$ \\
\hline Population coverage, $\%$ & $0.028 \quad(0.026)$ & $(0.005)$ & $0.021 \quad(0.013)$ \\
\hline Lambda: vaccination nest & - & $0.502^{b} \quad(0.195)$ & - \\
\hline Exempt status from travel restrictions ${ }^{a}$, no recent travel & - & - & - \\
\hline Exempt status from travel restrictions ${ }^{a}$, recent travel & $-1.273 \quad(1.138)$ & $-0.027 \quad(0.34)$ & $0.294 \quad(1.182)$ \\
\hline Delta & - & $-0.723^{c} \quad(0.186)$ & $0.295^{\mathrm{a}} \quad(0.165)$ \\
\hline Fee $^{a}$, non-White status & - & $-0.908^{b} \quad(0.753)$ & $1.785 \quad(0.934)$ \\
\hline Risk of illness ${ }^{a}$, aged $<60$ years & - & $(0.47)$ & $(0.384)$ \\
\hline Risk of illness ${ }^{a}$, non-White status & - & $(0.735)$ & $(0.486)$ \\
\hline Severe side effects ${ }^{a}$, non-White status & - & $(0.57)$ & $(0.695)$ \\
\hline Wait timea, non-White status & - & $-1.047^{b} \quad(0.802)$ & $4.057 \quad(3.277)$ \\
\hline Lambda: fee ${ }^{a}$, income & \multicolumn{3}{|c|}{$-0.127^{\mathrm{a}} \quad(0.072)$} \\
\hline Fee ${ }^{a}$, no reported income & \multicolumn{3}{|c|}{$1.727 \quad(0.816)$} \\
\hline \multicolumn{4}{|c|}{$\begin{array}{l}\text { Note: Coefficients represent the marginal effect of a change between class } 1 \text { and other classes. Standard errors are reported in parentheses. } \\
\text { a } P<0.05 \text {. } \\
{ }^{b} P<0.01 \text {. } \\
{ }^{c} P<0.001 \text {. }\end{array}$} \\
\hline
\end{tabular}

individual classes, we used posterior analysis to produce a membership profile for each class. We found that there were $8 \%$ more Black respondents in Class 1, compared with the sample mean, but $2 \%$ fewer in Class 2 and $5 \%$ fewer in Class 3 . In other words, relatively more Black respondents prefer vaccine options with a fee but no wait time, and fewer Black respondents prefer free vaccine options with a wait time or "no vaccine" options.
The opposite was true for respondents identifying as Asian: there were 10\% fewer Asian respondents in Class 1 than the sample mean, $42 \%$ fewer in Class 2, and 24\% more in Class 3. Thus, there are relatively more Asians 


\section{FIGURE 1 Reasons for Getting Vaccinated, by Race}

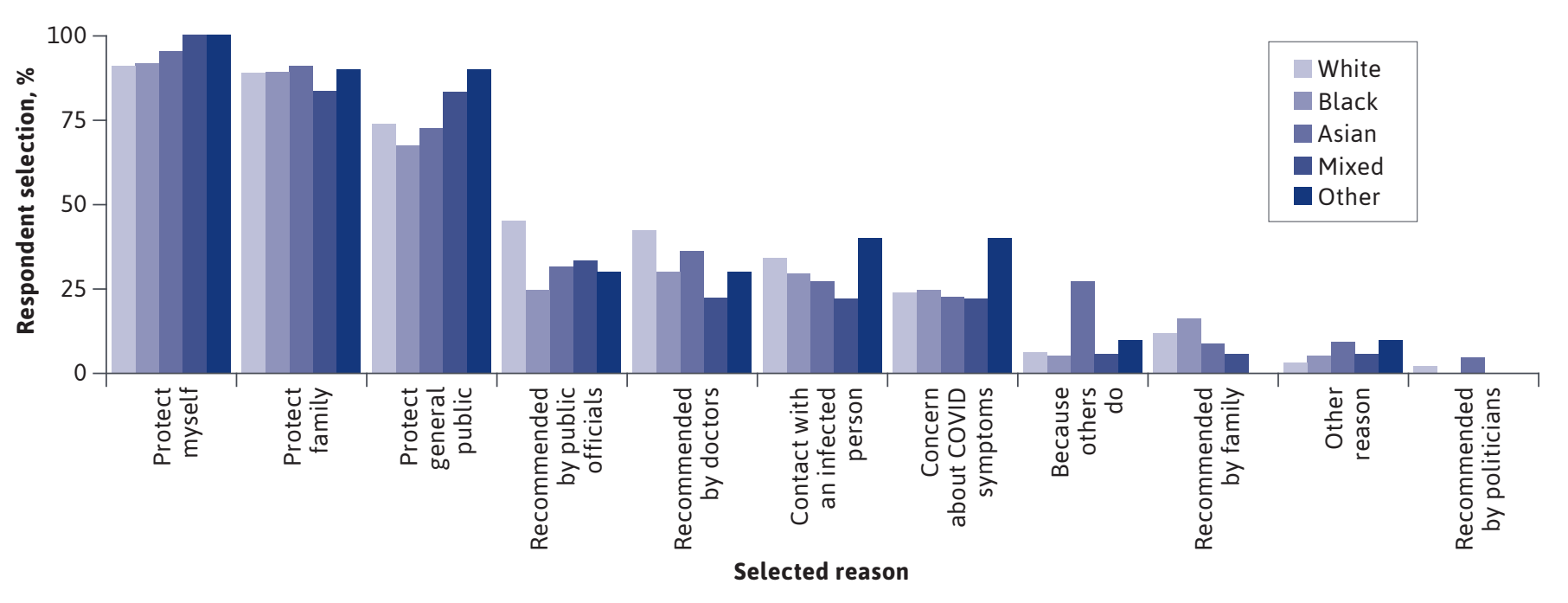

than the sample average to prefer free vaccine options with a longer wait time or no vaccine. We found a similar pattern for respondents with mixed or other race.

Table 4 reports the results of the latent class model including interactions with sociodemographic characteristics in the class membership model. We found that non-White respondents in Class 2 (the class with an overall preference for "no vaccine") were less likely to choose an option that involved paying a fee than White respondents within that class $(\beta=-0.908, \mathrm{SE}=0.753, P<0.001)$. We found that non-White respondents in Class 3 were more likely to choose an option that involved paying a fee that White respondents in that class $(\beta=1.785, \mathrm{SE}=0.934)$, although this effect was insignificant. We also found that non-White respondents in Class 2 were significantly less likely to shift to an option with a longer wait time $-(\beta=-1.047, \mathrm{SE}=0.802$, $\mathrm{P}<0.001)$. Non-Whites respondents in Class 3 were more likely to shift to an option with a longer wait time than their White counterparts in that class, although this effect was also insignificant $(\beta=4.057, \mathrm{SE}=3.277)$. In other words: nonWhite participants in Class 2, the class with the strongest overall preference for the "no vaccine" option, were less willing to pay and less willing to wait for a vaccine than White respondents within that class.

Household income was considered as income elasticity for cost (ie, fee) sensitivity, with a separate interaction for missing data for income. We found that those with a higher income $(>\$ 75,000)$ in Class 2 were less likely to be sensitive to changes in the fee for a vaccine. Respondents aged older than 60 years in Classes 2 and 3 were more sensitive to the risk of illness attribute than those younger than 30 years, and non-White respondents were also more sensitive to this attribute than White counterparts in Classes 2 and 3. We also looked at whether non-White people were more sensitive to mild side effects, the risk of infection, and duration of protection with a vaccine, but we found no significant difference with the White population in those classes.

\section{PREFERENCE ORDER}

Respondents in the survey were also asked to select reasons for getting a COVID-19 vaccine. Figure 1 shows the reported reasons for getting vaccinated, by race. Overwhelmingly, respondents across all races answered first "to protect myself." This was followed by "to protect my family" and "protect the general public," although fewer Black respondents picked this answer than White, Asian, mixed, and "other" races. Fewer Black respondents than others also picked "because it was recommended by public officials" and "because it was recommended by doctors." They were more likely to choose "because it was recommended by family" as a reason to get vaccinated.

\section{Discussion}

In this study, we sought to understand low vaccination rates among racial minorities. Overall, we found that individuals who self-report as Black had lower rates of vaccine hesitancy than those who identify as White. This was true overall, 
by latent class and within latent class. This suggests that, contrary to what is currently being reported, Black people are not universally more vaccine hesitant. Combining the respondents who would not consider a vaccine $(17 \%)$ with those who would consider one but ultimately choose not to vaccinate $(11 \%)$, our findings indicate that more than 1 in 4 (28\%) persons will not be willing to vaccinate. The no-vaccine rate is highest in White participants and lowest in Black participants.

This finding initially seems contrary to the widely reported lower vaccination rates for the Black population. What this study shows is that Black Americans, holding other factors constant, are more likely to vaccinate than White Americans. Yet other factors are not constant. Vaccine hesitancy varies by many other factors, including age, income, and education. Class 2 membership is higher among those aged between 41 and 60 years, lower income (less than $\$ 20,000$ per year), and, particularly, lower levels of education. The lower actual rates of vaccine hesitancy among Black participants are thus not necessarily a reflection of racism but rather reflect differences in preferences by income and education that cut across races, with Black Americans more likely to be in these low socioeconomic status groups. Blacks, then, are simply more prevalent within the already hesitant subgroups. Thus, to increase vaccination rates among the Black population, it will be necessary to focus attention on reasons for hesitancy among persons with less education and lower incomes.

This research also shows that grouping non-White people into broad categories like "persons of color" misses important differences among different racial groups and elements of identity intersectionality. Asian respondents were far less likely to be in the evaluative class and far more likely to be in in the cost-conscious class. The preference structure for Asian respondents is markedly different from Black respondents.

\section{LIMITATIONS}

One limitation of the segmentation analysis is that, due to sample size, we were only able to measure "nonWhite" effects within classes so we cannot report the effect of Black respondents and other races within classes. The analysis thus assumes homogeneous preferences among non-White participants for the withinclass analysis. It also does not consider differences in ethnicity. However, the (posterior) class profile analysis shows that Black participants generally preferred vaccine options without a wait time, whereas other races represented in our sample had overall preferences for "no fee" options or "no vaccine" options. This suggests that Black respondents within Class 2 may be even less willing to wait and less willing to vaccinate as the effects measured may be partly offset by the preferences of other non-White respondents. Another potential limitation is that some of the racial effects may be modified by income and education. Given the distribution of income, more work needs to be done to separate racial and income disparities.

\section{Conclusions}

Lower rates of vaccination among Black Americans do not reflect lower rates of racially motivated vaccine hesitancy. Instead, these lower rates reflect a higher proportion of Black people among groups with vaccine hesitancy-lower income and lower educated individuals. To reduce racial disparities in vaccination rates, it will be necessary to address vaccine hesitancy more broadly in disadvantaged populations.

\section{DISCLOSURES}

No funding was received for this study. The authors have nothing to disclose.

\section{REFERENCES}

1. Alvidrez J, Castille D, Laude-Sharp M, Rosario A, Tabor D. The national institute on minority health and health disparities research framework. Am J Public Health. 2019;109(S1):S16-20.

2. Kneipp SM, Schwartz TA, Drevdahl DJ, et al. Trends in health disparities, health inequity, and social determinants of health research: a 17-year analysis of NINR, NCI, NHLBI, and NIMHD funding. Nursing Research. 2018;67(3):231-41.

3. Pérez-Stable EJ, Collins FS. Science visioning in minority health and health disparities. Am J Public Health. 2019;109(S1):S5.

4. Centers for Disease Prevention and Control. How CDC is making COVID-19 vaccine recommendations. May 14, 2021. Accessed August 28, 2021. https://www. cdc.gov/coronavirus/2019-ncov/vaccines/recommendations.html

5. Belot M, Choi S, Jamison JC, Papageorge NW, Tripodi E, Van den Broek-Altenburg E. Unequal consequences of Covid 19 across age and income: representative evidence from six countries. Rev Econ Househ. 2021;1-15.

6. Papageorge NW, Zahn MV, Belot M, et al. Socio-demographic factors associated with self-protecting behavior during the Covid-19 pandemic. J Pop Econ. 2020:1-48

7. Wen LS, Sadeghi, NB. Addressing racial health disparities in the COVID19 Pandemic: immediate and long-term policy solutions. Health Affairs Blog. July 20, 2020. Accessed December 17, 2020. https://www.healthaffairs.org/ do/10.1377/hblog20200716.620294/full/

8. Jean-Jacques M, Bauchner H. Vaccine distribution-equity left behind? JAMA. 2021;325(9):829-30. 
9. Ndugga N, Pham O, Hill L, Artiga S, Mengistu S. Latest data on COVID-19 vaccinations race/ethnicity. August 4, 2021. Accessed December 17, 2020. https://www.kff.org/coronaviruscovid-19/issue-brief/latest-data-covid19-vaccinations-cases-deaths-raceethnicity/

10. Recht H, Weber, L. Black Americans are getting vaccinated at lower rates than White Americans. Kaiser Health News. January 7, 2021. Accessed December 17, 2020. https://khn.org/news/article/ black-americans-are-getting-vaccinatedat-lower-rates-than-white-americans /

11. Nephew LD. Systemic racism and overcoming my COVID-19 vaccine hesitancy. EClinicalMedicine. 2021;32:100713.

12. Bunch L. A tale of two crises: addressing Covid-19 vaccine hesitancy as promoting racial justice. HEC Forum. 2021;33 (1-2):143-54

13. Callaghan T, Moghtaderi A, Lueck JA, et al. Correlates and disparities of COVID-19 vaccine hesitancy. Soc Sci Med. 2021;272:113638.

14. Beckman AL, Forman HP, Omer SB. Four steps to help achieve COVID-19 vaccine adoption: how health professionals can embrace their role as messengers. Health Affairs Blog. January 21, 2021. Accessed December 17, 2020. https:// www.healthaffairs.org/do/10.1377/ hblog20210121.500910/full/
15. Bogart LM, Ojikutu BO, Tyagi K, et al. COVID-19 related medical mistrust, health impacts, and potential vaccine hesitancy among Black Americans living with HIV. J Acquir Immune Defic Syndr. 2021;86(2):200-07.

16. Anandappa M, Boakye EA, Li W, Zeng W, Rebmann T, Chang J. Racial disparities in vaccination for seasonal influenza in early childhood. Public Health. 2018;158:1-8.

17. Danziger J, Weinhandl E, Friedman D, Mukamal KJ. Racial and ethnic disparities in seasonal influenza vaccination among dialysis facilities in the United States. J Am Soc Nephrol. 2020;31(9):2117-21.

18. Lu P-J, O'Halloran A, Williams WW, Lindley MC, Farrall S, Bridges CB. Racial and ethnic disparities in vaccination coverage among adult populations in the US. Vaccine. 2015;33:D83-91.

19. Yoo B-K, Kasajima M, Phelps CE, Fiscella K, Bennett NM, Szilagyi PG. Influenza vaccine supply and racial/ethnic disparities in vaccination among the elderly. Am J Prev Med. 2011;40(1):1-10.

20. Schectman JM, Schorling JB, Voss JD. Appointment adherence and disparities in outcomes among patients with diabetes. J Gen Intern Med. 2008;23(10):1685.
21. Bernheim SM, Spertus JA, Reid KJ, et al. Socioeconomic disparities in outcomes after acute myocardial infarction. Am Heart J. 2007;153(2):313-19.

22. Bhandari VK, Kushel M, Price L, Schillinger D. Racial disparities in outcomes of inpatient stroke rehabilitation. Arch Phys Med Rehab. 2005;86(11):2081-86.

23. Khera R, Vaughan-Sarrazin $M$, Rosenthal GE, Girotra S. Racial disparities in outcomes after cardiac surgery: the role of hospital quality. Curr Cardiol Rep. 2015;17(5):29.

24. Rangrass G, Ghaferi AA, Dimick JB. Explaining racial disparities in outcomes after cardiac surgery: the role of hospital quality. JAMA Surg. 2014;149(3):223-27.

25. Bradley CJ, Given CW, Roberts C. Disparities in cancer diagnosis and survival. Cancer. 2001;91(1):178-88.

26. Morris AM, Rhoads KF, Stain SC, Birkmeyer JD. Understanding racial disparities in cancer treatment and outcomes. J Am Col Surg. 2010;211(1):105-13.

27. O'Keefe EB, Meltzer JP, Bethea TN. Health disparities and cancer: racial disparities in cancer mortality in the United States, 2000-2010. Front Public Health. 2015;3:51. 